\title{
Ordo amoris: fenomenología del amor en Max Scheler, orden y desorden del corazón humano
}

\section{Ordo amoris: The phenomenology of love in Max Scheler, order and disorder of the human heart}

Aceptación: marzo 2008.

Aprobación: julio 2008.

Juan Mansilla Sepúlveda'

\begin{abstract}
RESUMEN
Este trabajo presenta la fenomenologia scheleriana del amor tomada del acervo agustiniano que concibe al ordo amoris como el núcleo principal del ethos de un hombre o una colectividad humana: todo el obrar moral social nace de un amor fundamental, y ese amor es, a su vez, una amor plural, dirigido a muchos géneros de cosas, pero ordenado segùn un orden de importancia de éstas. Es, lisa y llanamente predilección. Las verdades se van fundando, en esencia, desde el orden y el desorden del corazón humano. El concepto de un ordo amoris tiene asi una significación doble: una significación normativa y una significación descriptiva. Los resultados de este estudio se orientan a que lo supremo a que el hombre puede aspirar, es amar las cosas, en la medida de lo posible, tal como Dios las ama, y vivir con evidencia, en el propio acto del amor, la coincidencia entre el acto divino y el acto humano en un mismo punto del mundo de los valores, indistintamente del juicio de la existencia de Dios.
\end{abstract}

Palabras clave: Fenomenología, ordo amoris, ethos, amor.

\begin{abstract}
This work presents the fenomenologia scheleriana of the love taken of the array agustiniano that conceives the ordo Amoris as the principal nucleus of the ethos of a man or a human collective: Everything to socially and morally speaking is born of a fundamental love, and this love is, in turn, one plural love directed many kinds of things, but arranged according to an order of importance of these. It is simply predilection. The truths start to found, in essence, from the order and the disorder of the human heart. The concept of an ordo Amoris has a double significance like that: a normative significance and a descriptive significance. The results of this study are orientated to that the supreme thing to which the man can aspire, is to love the things, as far as possible, such as God to love them, and to live with evidence, in the proper act of the love, through the coincidence between the divine act and the human act in the same point of the world of the values, indistinctly of the judgment of the God's existence.
\end{abstract}

Key words: Fenomenologia, ordo amoris, ethos, love.

Profesor de Historia, Geografia y Educación Civica. Doctor o Filosofia. Universidad Pontificia en Salamanca. jmansilla@uct.cl

DOI: 10.7770/CUHSO-V16N2-ART281 


\section{Problematización}

Tres preguntas han orientado esta investigación y son las siguientes:

a. ¿Cuál es el concepto y sentido de amor que describe Scheler desde una perspectiva fenomenológica?

b. ¿De dónde proceden los trastornos del ordo amoris normativo?

c. ¿Cuál es la articulación que se da entre el resentimiento y tesis socrática?

La primera pregunta pretende situar contextual y conceptualmente el amor desde la reflexión de Scheler, esto a partir de 'un abrir los ojos' para los valores más altos que les son dados al interés [aprehensión del valor más alto en su cualidad ideal].

Una segunda interrogante discute los trastornos de la expresión 'ordo amoris' tomada de San Agustín, la cual a mi juicio es entendida por Scheler $^{2}$ en tres sentidos: unas veces designa con ella el orden objetivo de los valores considerados en sí mismos. Otras veces hace alusión con ella a esa misma jerarquía, pero en cuanto conocida por el hombre, adquiriendo un significado normativo, como pauta a su voluntad, y finalmente da cuenta de ese orden jerárquico, en tanto núcleo principal del ethos de un hombre o una colectividad humana, en cuanto entrañado 'ya afectivamente' en el querer del hombre, inspirando de hecho su conducta [tensión ordo amoris normativo/ordo amoris descriptivo].

La tercera pregunta pone en discusión la articulación que se da entre resentimiento y restablecimiento scheleriano de la tesis socrática, para reivindicar la relación esencial entre la evidencia axiológica y la conducta voluntaria, lo que implica asumir el querer afectivo del sujeto respecto del saber del cual también es portador. Entonces, a continuación se desarrollarán todas estas preguntas, superponiéndose la reflexión, siempre desde el amor, siendo este el valor primero, que preside la vitalidad de la persona, ya que la sostiene y la lleva a su plenitud, complementado desde una mirada cristiana y analizando el significado fenomenológico de amor que le atribuye Scheler en su extensa obra, en tanto acto primigenio y espontáneo, abriéndose siempre al mundo de los valores.

El amor, de acuerdo a lo que se expone en esta investigación es una apertura radical hacia la objetividad, que fundamentaria tanto el conocimiento como la volitividad. En esto radica el papel creador del amor, que da la existencia a los valores, no en sentido absoluto, sino respecto de nuestra propia vida moral y de nuestras vivencias emocionales. Esta existencia de los valores es la única a la que tenemos acceso desde la fenomenología: la existencia como presencia objetiva en la conciencia emocional. Desde esta perspectiva, como se desarrollará en los apartados siguientes, el objeto del amor nunca es fin, y es que en el amor el valor aparece sin referencia ninguna ni a la existencia ni a la realización por parte de una tendencia o de la voluntad. La única existencia previa a la que hace referencia el amor es distinta tanto de la existencia empírica como de la ideal: es la pura referencia intencional del amor a una consistencia esencial objetiva del valor. De hecho, Scheler es preclaro en tanto niega que sea posible un amor al bien (moral) por sí mismo. El bien moral radicaría ante todo en el mismo amor, y por eso no puede darse el amor al bien, pues sería amor del amor mismo, amor de la propia existencia; y esto sería fariseísmo en su versión antigua; filantropía en su versión neoliberal; por eso es que el amor no surge de una reflexión que descubra objetivamente la bondad moral de realizar tal acto, sino que 'brota espontáneamente', antes de todo dominio de la persona sobre sus actos. El amor, para Scheler, no capta el bien como algo que merece ser realizado, pero que no lo será hasta que la libertad se decida por él. Por todo ello, el bien moral nunca es fin,

Ordo Amoris de Max Scheler es un texto fragmentario que no fue publicado por su autor. Vio la luz en 1933, un lustro después de su muerte, junto a otros trabajos inéditos de este redactados entre los años 1912 y 1916, publicados por su viuda, Maria Scheler, en el volumen titulado Schriften aus dem Nachalass, Band I, Zur Ethik und Erkenntnislehre (Escritos del legado póstumo, tomo I, Sobre Ética y Teoría del conocimiento), que constituye el tomo décimo de las obras completas del filósofo. 
sino que es la cualidad de una experiencia ligada al amor espontáneo.

2. Concepto y sentido de amor en Scheler desde una perspectiva fenomenológica

\subsection{Personalismo ético o la persona como un valor en sí mismo}

En cuanto al personalismo ético, Pintor Ramos (1997) deja claramente de manifiesto que la clave de la crítica de Scheler a la civilización vigente está en la progresiva tendencia despersonalizadora de esta. Dos características fundamentales cabe destacar en la concepción scheleriana de la persona: su transcendencia y su actualidad [sentido metafísico]. Lo que se denomina transcendencia podria entenderse 'fenomenológicamente' como 'intencionalidad', 'apertura'. Y es que el ser personal está abierto a la totalidad del mundo, donde "mundo" significa un horizonte abierto en el que se van integrando y ordenando las cosas físicas y todos los descubrimientos e innovaciones de la humanidad.

Entonces, de la misma forma que el organismo realiza funciones, la persona realiza actos, pero además la persona se realiza en los actos y solo es persona real en esa realización. Scheler se opone así a un substancialismo, en tanto toda persona es siempre individual, de tal modo que persona individual es una redundancia; pero individual no significa, necesariamente, 'singular'.

En este sentido, tres son las ideas de hombre que se disputan el escenario de la cultura occidental, a saber:

a. Desde ta exitosa idea de los griegos

b. Desde la idea del cristianismo

c. Desde el desarrollo biologizante

A partir de esto, huelga decir que Scheler ve al hombre como un microcosmos espiritual y vivo; donde como ser natural el hombre cae de lleno en el mundo de la vida, al que pertenece como último eslabón de su proceso evolutivo. No obstante, Scheler parece entender la vida como un mundo supraindividual, con cierta sustantividad. Esto nos lleva a hablar de un fenómeno que se ha denominado "unificación afectiva" (Scheler, 1961).

Y precisamente es aquí donde se sitúa Pintor Ramos, cuando descriptivamente nos dice que el hombre es un "microcosmos espiritual"; por eso Max Scheler afirma con rotundidad y densidad que la persona es un valor por sí misma ${ }^{3}$. Lo anterior nos hace caer en la cuenta que el hombre es mucho más que un sujeto portador de valores, ya que es un valor personal. Desde esta radical aseveración ontoaxiológica se da cuenta de la objetividad de los valores, Scheler sitúa a los valores en la siguiente jerarquía de cuatro categorías en un orden que va desde el más inferior al más superior:

(1) Valores sensibles: estados sensibles del placer y el dolor (existencia de una naturaleza sensible).

(2) Valores vitales: son los comprendidos en la antítesis "noble - vulgar", se corresponden con los modos del sentimiento vital.

(3) Valores espirituales: son independientes del cuerpo y del entorno y abarcan tres subgrupos:

a. Valores estéticos: antítesis bello-feo

b. Valores juridicos: antitesis justo-injusto

c. Valores lógicos: antítesis verdadero-falso

(4) Valores religiosos: antítesis sagrado-profano.

Esta escala axiológica nos lleva al núcleo de la filosofía de Scheler, apareciendo el hombre como un valor único en su género, un "universo personal" ya que es un microcosmos y un otorgador de sentido ${ }^{4}$.

Scheler, Max. Formalismus und die materiale Wertethik, Gesammelte Werke. 1954, p. 129.

Scheler, Max. El Puesto del Hombre en el Cosmos, p. 38. 
Scheler asegura que no hay valores porque haya bienes y fines (Santo Tomás), ni porque haya normas (Kant), ya que los valores son independientes de las cosas, cualidades a priori: "aunque nunca hubiera pensado nadie que la borrachera era mala", ella sería un mal de suyo. Asi pues, una ética a priori defenderá la inmutabilidad, inalterabilidad, absolutez e incondicionalidad del valor: solo nuestro conocimiento del valor puede ser relativo, no el valor mismo; por tanto, la irreductibilidad a la subjetividad: "hay infinito número de valores que nadie pudo hasta ahora captar ni sentir" (Scheler, 1941; p. 39).

Los entes son, existen en la realidad, pero los valores valen, y valen aunque nunca se hubieran hecho presentes en el mundo; los valores no son entes, ni tampoco propiedades de las cosas, ni son fuerzas, potencialidades, o disposiciones de las cosas capaces de causar en los sujetos los correspondientes estados, como quería Locke. Están, eso si, en las cosas fundándolas, pero no se reducen a la condición de cosas, pues la belleza es un valor que existe más allá de las cosas bellas, y su presencia seguiría ahí, incluso en un mundo completamente feo.

La independencia y objetividad de los valores no desaparece cuando el sujeto humano los percibe intencionalmente, tendiendo o apuntando hacia algo que no es la pura vivencia psíquica, de forma que al percibir se percibe algo, al recordar se recuerda algo, etc. pues el objeto se nos da como algo irreductible a la vivencia; y lo mismo sucede en el percibir sentimental que nos revela la presencia del valor: "el hecho fenomenológico precisamente es que en el percibir sentimental de un valor está dado este mismo valor, junto con el sentir del mismo, y por consiguiente la desaparición del percibir sentimental no suprime el valor en cuanto tal" (Scheler, 1941, p. 13).

Los valores "se manifiestan a la experiencia de las personas. En el sistema fenomenológico de Scheler, de las cosas o de nosotros mismos solo podemos afirmar o negar en tanto en cuanto se nos presentan, y en la medida en que se nos presentan en la intuición emocional, su densidad sin nuestra objetivación nos resultan ignotas. Para decirlo fenomenológicamente, los valores se nos revelan en el percibir sentimental, en el preferir, amar, odiar" (Scheler, 1941, p. 108).

\subsection{El amor en Scheler}

"Ama y haz lo que quieras" (San Agustín de Hipona)

Desde el punto de vista de la ética kantiana, según Pintor Ramos, Scheler rechaza la postulación de una ética filosófica formal, en tanto intenta fundar una ética material (con contenidos concretos y no mero formalismo) [pp. 22, 23]. Esto implica revisar la tesis kantiana del 'Apriorismo', lo cual se posibilita si es que nos posicionamos desde una perspectiva fenomenológica de la intuición esencial. Como se puede ver, Scheler rechaza un 'deontologismo puro'. En esta contingencia, Pintor Ramos cita a Brentano ${ }^{5}$ [p. 23] y asi relevan las contribuciones más importantes:

i. Su conocida clasificación de los fenómenos psíquicos reserva para los actos de amor y odio, un grupo propio, al lado de las representaciones y de los juicios, lo cual los hace inderivables e irreductibles a los actos intelectuales.

ii. Los actos de amor y odio son intencionales, lo cual abre una vía para rescatarlos de su 'supuesta' irracionalidad y así verlos como fuerzas que nos abren a amplias zonas de lo real, inaccesibles para la pura razón [p. 23].

Es así como respecto de la oposición razón/sentimiento, Scheler piensa que se trata de un 'inveterado prejuicio' que utiliza el término sentimiento como cajón de sastre en el que se mezclan de manera confusa cosas tan distintas.

$\mathrm{El}$ amor es decisivo en un pensamiento contundente, de una densidad radical: "antes que Ens Cogitans o Ens Volens, el hombre es un Ens Amans" [SN356] (p. 26). Este

s No obstante, el intelectualismo de Brentano deja damnificado al sentimiento. 
es el núcleo de su concepción de hombre. En este escenario vital, el amor no es un simple conglomerado de estados afectivos en los que se asocian ciertos impulsos: el amor aparece como un fenómeno originario, intuible, nunca definible [WFS, 155].

Por tanto, tres aspectos fundamentales están presentes en la descripción del amor, como cualidades de acto:

a. El amor es un movimiento, lo cual se opone a las múltiples concepciones que han denominado al "amor" como un estado del sujeto, sea este un estado sensible, psíquico o patológico.

b. El movimiento del amor se dirige siempre a un objeto individual en cuanto portador de valores, no hay amor a entidades abstractas o ideales. No existe un amor a los valores puros; como tampoco existe un amor al bien. El amor no se dirige a realidades individuales en su específica objetividad, sino, como se dijo, en tanto individuos portadores de valores. Esto quiere decir que la función del amor no es crear los valores mismos o idealizar a individuos portadores de valores. La función del amor es descubridora: es el acto que desvela los valores que en un individuo permanecen ocultos antes de la mirada del amor. Por eso Scheler se opone con fuerza a la idea tan difundida de que el amor es ciego.

c. La dirección del movimiento del amor marcha en su objeto desde el valor más bajo hacia el valor más alto, el inagotable objetivo que mantiene en marcha el amor es descubrir los valores más altos que puede realizar el objeto amado.

Unido a lo anterior hay varias ideas fuerzas que se desprenden: a. El amor ama y ve en el amar algo más que lo que posee en sus manos. Puede fatigarse el impulso que lo desencadena, pero el amor mismo no se fatiga.

b. Existe una ilimitación positiva y negativa de amor, vivida por nosotros como una potencia $y$, por tanto, también como una tendencia que se apoya sobre el acto del amor

c. Dios y solo Dios es la cúspide de la arquitectura gradual y piramidal de lo amable, fuente y fin de todo Él6.

d. El ánimo, en tanto corazón humano es el reverso articulado del cosmos de todos los posibles caracteres amables de las cosas, por lo tanto, es un microcosmos del mundo de los valores. "El corazón tiene sus razones que la razón no logra percibir" [en el sentido de motivos, deseos, no determinaciones objetivas estrictas]. Es esta la convicción de Pascal, quien estuvo convencido desde un comienzo que el amor, incluso más que la razón, tenía algoritmos precisos.

\section{Ordo amoris: cultura del corazón?}

[Ordo amoris], es el amor ordenado ${ }^{8}$ [ordinata dilectio] del que ya hablaba San Agustín ${ }^{9}$. La mente privilegiada de Agustín de Hipona condensó de manera extraordinaria todo esto en una expresión inigualable: "ordo amoris". Por lo tanto, existe un orden del corazón, una lógica del corazón, rigurosa y radicalizante, absoluta e inquebrantable. Tal es la omnipresencia y la oculta importancia que este tiene en la vida moral de cada hombre o colectividad humana, que justamente, por eso, si algún ser pretendiera y pudiera juzgarla moralmente, tendría para hacerlo que escudriñar en estos el orden de su amor, tal como nos previene que se hará con nosotros

- En este sentido es interesante revisar lo que dice San Pablo: "Quisiera estar apartado eternamente de Dios por amor de mi amigo y de Dios" (Romanos 9, 3). Apartarse de Dios por un instante significa estar apartado de Dios eternamente. San Pablo renunció a Dios por amor de Dios, renunció a todo cuanto podia recibir de Dios, y renunció a todo cuanto Dios podía darle y a todo cuanto podía recibir de Dios. Dios quedó para él tal como es esencialmente en si mismo, no según su modo de ser recibido o conquistado, sino en su esencia primigenia que es Dios en si mismo.

7 "Nuestro corazón es demasiado vasto" [Pascal].

8 Scheler, M. Ordo Amoris. GW 10, 347-348.

9 Cf. San Agustín, 'De Doctrina Cristiana. L.I, c. XXVII, 28. 
al declinar el día el místico castellano: "A la tarde te examinarán en el amor"10.

Todo el mundo es un ámbito que viene del amor y está orientado al amor. La vida del hombre está ordenada dinámicamente hacia el ideal de la unidad, que es ideal de amor mutuo, comprometido en la creación de formas de unidad estables y fecundas. Al orientar la vida hacia este ideal, se ama lo que es amable, se repudia lo que es desechable. De este modo, se ama ordenadamente, conforme a lo que su razón le dicta que es su vocación y su destino, es decir: la verdad de su vida, su autenticidad. La verdad es la manifestación de la realidad, la cual está constituida por interrelaciones. Esta verdad no es ni objetiva ni subjetiva, sino relacional, propia del sujeto y del objeto vistos en relación.

Desde esta perspectiva es interesante revisar la interpretación scheleriana de la sensibilidad franciscana ${ }^{11}$. San Francisco de Asís, entonces, es un genio del pensamiento, fue capaz de tomar altura y sobrevolar cuanto veía y supo descubrir el sentido de lo que existe, nos ayudó a abrir los ojos para advertir que el universo está maravillosamente ordenado, de forma que todo parecía indicar que una mano amorosa lo creó y lo destinó a ser escenario de vidas consagradas a crear vínculos de amor, tal vez como él mismo jamás imaginó.

El ordo amoris, la ordenación que viene del amor y está llamada a crear más amor, debe ser fundado por el ser humano en relación a las realidades de su mundo [entorno], que están de por sí abiertas a la interrelación compleja. Esa fundación se da en las diversas formas de encuentro que puede y debe el hombre crear. No es una tarea que dependa solo de él, pero tampoco le viene impuesta de modo necesario. Está llamado a realizarla dentro de las condiciones concretas de las situaciones en que se halle. Se trata, por tanto, de una vocación y una misión que ha de realizar dentro del contexto de su particular destino.
La tradición cristiana, cuya doctrina se centra en la convicción de que "Dios es amor, y quien permanece en el amor permanece en Dios y Dios en él" (1 Jn 4, 16). Esto nos permite formular lo antedicho de modo transparente: En medio de las realidades creadas por Dios con un espíritu de amor, el ser humano debe configurar su "mundo" propio amorosamente, con vistas a crear nuevas y más elevadas formas de unidad. Tener un amor ordenado es vivir de modo justo, ajustado al 'ordo rerum', a la ordenación de cuanto existe.

En este contexto es interesante citar la 'introducción' de la última Carta Encíclica Deus Caritas Est del Sumo Pontífice Benedicto XVI a los obispos, presbiteros, diáconos, a las personas consagradas y a todos los fieles laicos sobre el amor cristiano. Citamos textual a Joseph Ratzinger ${ }^{12}$ :

"... Hemos creido en el amor de Dios: así puede expresar el cristiano la opción fundamental de su vida. No se comienza a ser cristiano por una decisión ética o una gran idea, sino por el encuentro con un acontecimiento, con una Persona, que da un nuevo horizonte a la vida $\mathrm{y}$, con ello, una orientación decisiva. En su Evangelio, Juan habia expresado este acontecimiento con las siguientes palabras: "Tanto amó Dios al mundo, que entregó a su Hijo único, para que todos los que creen en él tengan vida eterna" (cf. 3, 16). La fe cristiana, poniendo el amor en el centro, ha asumido lo que era el núcleo de la fe de Israel, dándole al mismo tiempo una nueva profundidad y amplitud. En efecto, el israelita creyente reza cada día con las palabras del Libro del Deuteronomio que, como bien sabe, compendian el núcleo de su existencia: "Escucha, Israel: El Señor nuestro Dios es solamente uno. Amarás al Señor con todo el corazón, con toda el alma, con todas las fuerzas" $(6,4-5)$. Jesús, haciendo de ambos un único precepto, ha unido este mandamiento del amor a Dios con el del amor al prójimo, contenido

10 San Juan de la Cruz, Dichos de Luz y Amor, p. 59.

1 Rodriguez Duplá, L. San Francisco de Asis visto por Max Scheler.

12 Introducción. 'Deus Caritas Est' [Dios es amor], p. 1. 
en el Libro del Levitico: "Amarás a tu prójimo como a ti mismo" (19, 18; cf. Mc 12, 29- 31). $Y$, puesto que es Dios quien nos ha amado primero (cf. $1 \mathrm{Jn} 4,10$ ), ahora el amor ya no es solo un "mandamiento", sino la respuesta al don del amor, con el cual viene a nuestro encuentro...".

En este mensaje está contenida la unidad del amor en la creación y en la historia de la salvación y se asume primariamente como un problema de lenguaje, donde se plantean preguntas decisivas sobre quién es Dios y quiénes somos nosotros, aun cuando el tema de esta encíclica se concentra en la cuestión de la comprensión y la praxis del amor en la Sagrada Escritura y en la tradición de la Iglesia Católica. Además, se hace referencia al significado que tiene este vocablo en las diversas culturas y en el lenguaje actual. Todo amor, en Scheler, es un amor hacia Dios, donde el sentido socrático del término vuelve a mostrarse, en tanto lo que llamamos conocer [relación ontológica] supone siempre este acto primario y radical: un abandonar su propio ser y sus estados, sus propios contenidos de conciencia, donde Dios es el centro personal del mundo, en tanto que cosmos y en tanto que todo. Los fines e ideas esenciales de todas las cosas son ya amados y pensados por Él. En este sentido, para Scheler, el ordo amoris es el núcleo del orden del mundo como orden divino, en cuyo orden, también se halla el hombre como el más libre de los servidores de Dios y el más digno de servirle.

El ordo amoris viene a convertirse para el hombre en un ordo amorum, una ordenación de los amores, una explicación de la complejidad humana. El amor, rectamente entendido, se convierte así en criterio máximo de actuación. San Agustin lo expresó con magistral concisión: "Dilige, et quod vis fac": "Ama con amor, benevolencia, y haz lo que quieras", pues "si amas de verdad, no es posible que hagas sino el bien". El amor verdadero es el canon de la libertad auténtica.

Esto es mucho más complejo y enriquecedor si constatamos que para Scheler la meta y el sentido de la historia universal estriban en el perfeccionamiento moral de la humanidad. Este progreso moral de la humanidad no se verifica en el plano del hacer [metodológico-pragmático] o en el del conocer [epistemológico-gnoseológico], sino en el plano del ser [ontológico]. Dicho de otro modo, el progreso moral no consiste propiamente en que abunde cada vez más la conducta atenida a las normas que se fundan en la jerarquía objetiva de los valores, ni tampoco en que se generalice el conocimiento de esas normas y valores, sino en que los propios sujetos personales se vuelvan mejores, una 'mejora óntica', lo que se traduce en una superior sensibilidad moral, lo cual a su vez será más concordante con las exigencias del valor.

Entonces, para Scheler el estrato más básico de la vida personal es de naturaleza emocional. Somos, ante ninguna otra cosa, un sistema de amores y odios, de preferencias y desdenes, que Scheler denomina con expresión agustiniana, 'ordo amoris': "Quien posee el ordo amoris de un hombre, posee al hom. bre" (GW 10,348). Entonces ese progreso moral de la humanidad consiste ante todo en la mejora del ordo amoris de los individuos y de las colectividades, esto implica entender que la particular escala de valores de un individuo no agota el orden objetivo de los valores, la enriquece. En esto se funda el 'perspectivismo axiológico'. Esto debe ser más precisado aún, pues la diversidad de las morales que se registran en la historia no constituye, por tanto, un argumento a favor del relativismo que niega la objetividad de los valores, sino que se explica por el hecho de que el reino de los valores no se rinde en bloque al primer embate del amor. Ese reino es 'objetivo', pero su conquista es lenta y gradual, es una tarea colectiva del mundo.

Scheler denomina 'ethos' al conjunto de valores jerárquicamente ordenados accesible a los sentimientos de valor y a los actos de preferir y postergar de un individuo o sociedad. Esto nos recuerda que los actos emocionales de orden superior: amar, sentir valores, preferir, ocupan en esta filosofía el estrato más profundo de la vida espiritual. La historia es, ante todo, historia de lo sentimientos.

Respecto de la pregunta ¿por qué va cambiando el ethos de los individuos y los grupos sociales? La respuesta de Scheler está contenida en su doctrina de los modelos (Vorbilder), hombres y mujeres extraordinarios 
que, por la relación que guardan con algún ámbito de la esfera del valor, encarnan de manera ejemplar un "tipo ideal de persona" y fomentan con su ejemplo, muchas veces sin proponérselo, el crecimiento moral de los demás hombres. El influjo que estos hombres ejemplares ejercen sobre la sociedad explica que en ella, como en cualquier otra realidad personal, predomine una "dirección fundamental del amor y del odio".

Según Scheler (1961) dada la limitación del corazón humano, la contribución del hombre ejemplar se realizará en una sola de las dimensiones fundamentales del mundo del valor, nunca en varias. Teniendo a la vista esas dimensiones, Scheler nos habla de 'tipos de personas de valor', que no son sino los géneros supremos bajo los que cae cualquier modelo. Los tipos de persona de valor distinguidos por Scheler son:
a. El santo
b. El genio
c. El héroe
d. El espíritu líder la civilización
e. El artista del placer

Cabe decir que el influjo que ejerce el modelo sobre los demás hombres no es programado. El modelo no decide serlo, muchas veces hasta ignora su condición de tal. En esto se distingue del líder, que llega a serlo porque se ha propuesto explícitamente asumir esa función. Las consignas del líder se dirigen a la voluntad de las personas marcándoles una pauta de acción. El modelo, en cambio, opera de manera misteriosa, a menudo inconsciente, sobre el ser de las personas. El seguimiento del modelo, la imitatio, no consistirá, por tanto, en obediencia, sino en transformación del propio ser personal mediante la asunción del 'perfil axiológico'. Esto en el marco que el fondo último de la persona lo constituye el ordo amoris del individuo. De acuerdo con esto, la transformación del ser personal del seguidor será antes que cualquier otra cosa una transformación del corazón: estar bajo la influencia de un modelo, de un hombre ejemplar, es compartir su amor, amar lo que él ama.
El ascendiente de los modelos sobre la sociedad no es, según Scheler, un factor más en la transformación moral de los grupos humanos, sino el factor decisivo. Su eficacia es muy superior a la de otros factores, como el cumplimiento de las órdenes de la autoridad, la observancia de las leyes o la misma educación moral.

El amor es la tendencia, el acto que trata de conducir cada cosa hacia la perfección de valor que le es peculiar, no olvidando que para Scheler la esencia del amor es, por tanto, la acción edificante y edificadora en y sobre el mundo ${ }^{13}$. Entendido asi el amor, es pura engeneración del brotar de las cosas hacia la dirección divina.

\section{Pedagogía y ordo amoris}

Para promover el ordo amoris en la enseñanza el profesor o profesora debe cultivar el corazón, que es el hábitat de la afectividad y los sentimientos. Al depreciar los sentimientos, por considerarlos como meros estados subjetivos y arbitrarios del ser humano, se restó importancia al papel que juega el corazón en el proceso de desarrollo auténtico. Debemos distinguir los sentimientos de las sensaciones o impresiones, y, dentro de los sentimientos propiamente dichos, hemos de reconocer la existencia de modos diversos. Los sentimientos no se reducen a meras afecciones subjetivas; son la vibración de una persona ante una realidad que le afecta.

Tener buen corazón significa adoptar una actitud básica de entrega, ser sensible a la llamada de los valores más elevados y estar dispuesto a asumirlos con toda el alma, como pedía Platón. Esta prontitud para ir al encuentro de los valores implica la forma acogedora de escuchar lo que los latinos llamaban "ob-audire" (oir de forma penetrante), término del que se deriva "obediencia". Se trata de una "obediencia nutricia" que nos vincula para enriquecernos y hacernos plenamente libres, seres abiertos a la creatividad.

\footnotetext{
13 Scheler M. Ordo Amoris, p. 43.
} 
Por eso, allí donde no existe amor no hay más que problemas de carrera, de dineros, de quejumbre estructural, de angustia, que hoy la postmodernidad denomina ansiedad, de fastidio para el discípulo. La misión del educador, leído desde Scheler, supone evidentemente la fe, fe en la cultura y fe en las posibilidades del espíritu humano.

\section{Preferir y elegir en la ética de Scheler}

\subsection{Preferir}

Para el análisis del preferir es interesante revisar a Palacios (2002), quien claramente identifica que los actos de 'preferir' no son originariamente actos de juzgar, se decir, de afirmar o negar que una cosa es mejor o peor que otra ${ }^{14}$. Tampoco son actos de 'elegir', es decir, de querer una cosa en vez de otra, y es que los actos de elegir no pertenecen a la esfera de la elección, que son vivencias de naturaleza conativa. Entonces, los actos de preferir y postergar, para Scheler, pertenecen al campo emocional, junto a las funciones del sentir intencional y los actos de amor y de odio, como sentimientos intencionales de valor. Palacios cita a Franz Brentano quien habia advertido que el 'preferir' se caracteriza por ser "un amor que relaciona"15, que supone al menos dos objetos amados: el preferido y el postergado, donde la diferencia entre uno y otro es una distinción cualitativa. Esto implica clarificar que para que se dé un acto de preferencia, tengan que estar presentes al sujeto dos o más bienes o valores, esto quiere decir, que una acción puede dársenos como claramente "preferible" sin que pensemos necesariamente en alguna otra acción alternativa.

\subsection{Elegir}

Palacios hace la distinción, de manera bastante clara respecto de lo que implica 'preferir' y 'postergar' en relación a 'elegir'.
El sentido del 'preferir' está situado entre valores (fenómeno emocional), mientras que todo elegir tiene más bien sentido entre un hacer y otro hacer, es decir, entre acciones (fenómeno tendencial) ${ }^{16}$. Desde esta perspectiva se distinguen cinco formas diversas de tender:

(i) El mero impulso de movimiento.

(ii) Tendencia de salida o de separación.

(iii) Tendencia con una dirección original.

(iv) Dirección determinada por un contenido de valor al que apunta, pero no va acompañada de conocimiento alguno que pueda suponer un objetivo.

(v) Tendencia hacia algo preciso [su objetivo], que contiene dos componentes esenciales:

a. Componente de valor: se presenta siempre claro.

b. Componente de imagen: puede darse desde el 'brillo' por su ausencia hasta llegar a distintos grados de claridad y distinción.

Scheler estriba en las tres afirmaciones siguientes en las relativas a la relación general de estos dos componentes del objetivo:

Primera: que, en el orden del conocimiento, el componente de valor está dado en el tender de manera perfectamente clara y distinta, mientras que el componente de imagen puede no estarlo en absoluto o estarlo en todos los posibles grados de claridad y distinción.

Segunda: que, en el orden del ser, es el componente de valor el que determina y limita el ámbito de los posibles componentes de imagen en que puede realizarse.

Tercera: que, en el orden de llegar a ser, como los valores se captan en un sentir intencional y un sentir semejante se en-

14 Juan Miguel Palacios. "Preferir y elegir en la ética de Scheler", en Revista de Occidente [2002], p. 40.

15 Franz Brentano, Grundlegung und Aufbau der Ethik. Nach der Vorlersungen über "Praktische Philosophie" aus dem nachlass hrsg, von Franziska mayer-Hillebrand. A. Francke Verlag, Bern, 1952: p. 43.

16 Con esto Scheler en su perspicaz fenomenologia del tender, advierte Juan Miguel Palacios, logra hacer ver la falsedad de la tesis de que todo tender supone un conocimiento de su objeto, tal cual lo expresa el ignoti nulla cupido de Ovidio [Ars amatoria III, 397]. 
cuentre siempre inmanente a este género de tendencia, el componente de valor captado en él ejerce necesariamente una causalidad tractora respecto a la venida a la realidad del componente de imagen o significación de la tendencia. Como se puede apreciar toda motivación es causalidad inmediatamente vivida, a saber, en sentido eminente, "causalidad tractora".

En su fenomenología de la acción, Scheler cree que se pueden distinguir seis extremos:

$1^{\circ}$ La presencia de la situación y el objeto de obrar.

$2^{\circ} \mathrm{El}$ contenido que ha de ser realizado mediante la acción [el objeto práctico].

$3^{\circ}$ El querer ese contenido.

$4^{\circ}$ El llamado querer hacer.

$5^{\circ}$ Los estados de sensaciones y sentimientos ligados con aquellos.

$6^{\circ}$ La denominada ejecución de ese contenido.

En esta categorización la elección de una acción afecta de algún modo a todos ellos, pero sobre todo al tercero, que es el querer ese contenido práctico y, dentro de él, al último de los estadios que incluye, la disposición de ánimo, la intención, la reflexión, el propósito y la decisión. Elegir una acción, es, pues, ante todo decidirse a hacer una cosa en vez de otra, esto es posible gracias al sujeto volente que somos.

La elección será moralmente correcta cuando el que la hace se pliega al orden de los valores, eligiendo lo superior en detrimento de lo inferior. Y será moralmente incorrecta cuando el que la hace no se atiene al orden de los valores, eligiendo lo inferior en detrimento de lo superior. Pues, como escribe Scheler, "nuestro querer es bueno en la medida que elige el valor más alto de las inclinaciones"17. El orden de lo emocionalmente preferido -ordo amoris en sentido normativo- y el orden de lo efectivamente elegido -ordo amoris en sentido descriptivo- semejan ser dos órdenes distintos, y de la coincidencia o discrepancia del segundo con el primero parecen depender esencialmente los valores de la bondad o la maldad moral del querer y del que quiere.

\section{c. La relación entre preferir y elegir}

Lo interesante de esta relación es que para la voluntad de un ser cuyo sentir y preferir sean plenamente adecuados, resulta superflua y carente de sentido toda obligatoriedad moral. Esta misma correspondencia es la que rige la relación entre las dos formas de autonomía del querer de la persona distinguidas por Scheler: la autonomía de la evidencia moral y la autonomía del querer de la persona lo evidentemente bueno.

En este contexto, hay un singular vínculo entre el valor sentido y el objeto pretendido por el sujeto volente, se pone de manifiesto en la crítica y la reconstrucción scheleriana del concepto kantiano de disposición de ánimo (Gesinnung). Al respecto, Scheler la concibe más bien como una dirección hacia determinados valores materiales positivos o negativos, solo dentro de cuyos límites puede luego tener lugar la formación de la intención propiamente dicha.

Scheler dice: "Su querer determinado estados de valor y el mundo en el que él los "quiere" realizar "corresponden" por eso siempre en cierto sentido uno a otro, pues dependen por ambas partes, de las cualidades de valor presentes en su "disposición de ánimo" y de su orden jerárquico.

Según Scheler ${ }^{18}$ "el hombre no prefiere siempre las mismas cosas y los mismos hombres; pero sí las mismas clases de hombres y de cosas, clases que son en todo caso clases de valores que le atraen conforme a ciertas reglas constantes del preferir o del posponer lo uno por los otro, y que le atraen y le repelen dondequiera que vaya". En este atraer y repeler se oculta el ordo amoris del hombre. Es interesante apreciar que Scheler insiste en clarificar que en las personas no varía el mundo circundante con los cambios que de hecho

\footnotetext{
GW 2, 62.

18 Ordo Amoris. Op. cit., 28, 29.
} 
sufre dicho mundo. Scheler, asimismo, será enfático en decir que "Destino y mundo circundante reposan sobre los mismos factores del ordo amoris del hombre".

\section{Trastornos del ordo amoris normativo}

\section{1. ordo amoris normativo y descriptivo}

Una época histórica, una familia, un pueblo, se pueden comprender más a fondo si se reconoce el sistema siempre articulado de sus valoraciones fácticas y de sus preferencias de valor. Scheler denomina a este sistema explicitamente ethos ${ }^{19}$; siendo su núcleo fundamental el orden del amor y del odio.

Entonces, para Scheler, el concepto de un ordo amoris tiene un significado doble: un significado normativo [que es el que debe tener, el deber ser ideal] y un significado descriptivo [empírico-fáctico, lo que el hombre es realmente, debido a su libertad]. Esta reflexión es compleja debido a que la persona debe entenderse como ordo amoris normativo, pero también es ordo amoris descriptivo. En este sentido, el ordo amoris normativo es fundamental, en tanto esencialismo, frente al existencialismo, por ejemplo, heideggeriano. Entonces, el problema central en la teoria scheleriana consiste en pensar la articulación del ordo amoris normativo y el ordo amoris descriptivo. En este contexto son interesantes las reflexiones realizadas por Pilar Fernández Beites ${ }^{20}$, en particular, respecto del ordo amoris normativo, el cual no se entiende solo como un conjunto de normas ofrecidas a la voluntad, ya que afectivamente corresponde al territorio del ser. Respecto de esto, pareciera que Scheler entiende el ordo amoris normativo como "una determinación individual", lo que, por cierto, seria opuesto a destino, que sería lo externo al hombre, o sea, to que el hombre no es; aun cuando el destino viene marcado por las determinaciones individuales. Pilar Fernández intenta reconstruir la teoría scheleriana del ordo amoris al amparo de las distintas denominaciones que aparecen en sus escritos. Identifica las siguientes acepciones:

a. Ordo amoris normativo como "determinación individual" (individuelle Bestimmung)

b. Ordo amoris como esencia de valor (wertwesen)

c. Ordo amoris en tanto imagen ideal de valor (wertidealbildes)

d. Esencia de valor como 'salvación personal'

e. Ordo amoris normativo y descriptivo como un carácter en sentido estricto.

\subsection{Desorden del justo ordo amoris}

El desorden del corazón ${ }^{21}$ también se entiende como 'trastorno del ordo amoris'. Esta pregunta plantea el desafío casi pedagógico del restablecimiento del justo ordo amoris. Esto en la tesis scheleriana estaría dependiendo del ideal de salvación del sujeto en cuestión y de la determinación individual de la salvación, fundamentalmente. Lo anterior implica no perder de vista que la idea de un justo auténtico ordo amoris tiene directa relación con la idea de un reino de caracteres amables con todas las cosas, ordenadas con rigor objetivo y radicalidad axiológica. En este contexto la "determinación" expresa el lugar que pertenece a este sujeto en el plan de salvación del mundo. Aquí cabe decir que la 'determinación individual' no es 'subjetiva' por el hecho de que pueda ser conocida y realizada exclusivamente por aquel para lo cual existe. En este sentido Scheler, reconoce que es muy posible que otro conozca tal vez más adecuadamente que yo mismo mi determinación individual.

La "determinación individual" del hombre no es su destino, ya que el destino brota de la vida del hombre, es un cierta variedad de amor, to que tiene que preceder al conocimiento de la determinación individual, es el legítimo amor propio, o amor a su propia salvación, distinto de todo amor a si mismo. En el amor a si mismo to vemos todo con nuestros ojos, por lo que no llega a consti-

19 Libro sobre el Formalismo [GW2, V, 6].

20 Fernández Beites, P (2003) "Ordo amoris normativo y persona como ser ideal". Universidad Pontificia de Salamanca.

21. Pascal, Blaise. 
tuirse jamás en clara conciencia. En cambio, el verdadero amor propio implica una mirara espiritual, un mundo humano supramundano, nos vemos de manera objetiva $y$, en segundo lugar, como miembros del universo entero.

Una de las consecuencias del amor injusto o trastornado es el acto del odiar. En este odiar hay una ley: todo acto de odio se halla fundado en un acto de amor ${ }^{22}$. El amor y el odio en este entendido tiene de común un fuerte interés por los objetos de valor, donde el odio es siempre un amor vuelto del revés, donde el odio siempre reposa sobre la desilusión de la realización o no realización de un valor que intencionalmente e llevaba ya en el espíritu. Entonces, para Scheler como amor y odio son comportamientos emocionales opuestos, es imposible amar y odiar lo mismo en un mismo acto respecto del mismo valor, ya que nuestro corazón está hecho primariamente para amar y no para odiar, donde el que puede amar, no puede odiar. El odio es, por consiguiente, siempre y en todas partes, una rebelión de nuestro corazón y de nuestro espíritu contra la vulneración del ordo amoris.

Frente a la pregunta ¿cómo puede obtenerse en un sujeto el restablecimiento [en lo posible] del justo 'ordo amoris'?, Max Scheler va situarse desde dos perspectivas:

a. Depende del ideal de salvación del sujeto en cuestión.

b. Depende de la psicodinámica ya conocida del 'ordo amoris'.

De lo anterior se infiere que la idea de 'ordo amoris' justo y verdadero es la de un reino de caracteres amables de todas las cosas, ordenadas con rigor objetivo e independientemente de los hombres: algo que nosotros 'no hacemos', que 'no ponemos'; asi también la determinación individual de un sujeto es algo que por su especial contenido de valores afecta y mita solamente a él, tampoco 'se pone', solo 'se conoce'. Esta determinación expresa el lugar que pertenece a este sujeto en el plan de salvación del mundo [su oficio, su faena]. Si tratamos de medir y juzgar a un sujeto de modo moralmente completo, tendremos que tener ante nuestro espíritu la idea de la determinación individual exclusiva de él, y no la nuestra o la de otro sujeto ejemplar. En esta problemática esencial reaparece la pregunta relacionada con las formas de aprehensión de 'la determinación', la cual se lograría 'viendo' las manifestaciones vitales de cada persona, sus verdaderas intenciones, solo esto nos permitirá formar en nuestra conciencia una imagen integral superior a la realización empírica, fáctica, siempre fragmentaria que no reconoce el tejido auténtico de la complejidad humana. Es así como la determinación individual -no la subjetiva- se da, por el hecho de que puede ser conocida y rechazada exclusivamente por aquel para el cual existe, entonces, es muy posible, dice Scheler [p.118] que otro conozca tal vez más adecuadamente que yo mismo mi determinación individual, y que ese otro puede cooperar activamente en su realización. Estar ahí, existir para los demás, significar algo para ellos, compartir sus creencias, compartir su fe y sus esperanzas [sus angustias, hoy escondidas en el manto de la depresión y el estrés] es una parte de la determinación universal de todo ente espiritual infinito. Es en razón de lo anterior que la determinación individual puede hallarse en parcial coincidencia, o en pugna parcial con la estructura del mundo circundante y de su destino.

\section{El resentimiento y tesis socrática}

\subsection{Amor y resentimiento}

En el libro El resentimiento en la moral, capítulo I "Sobre fenomenología y sociología del resentimiento", Scheler da cuenta de los escasos descubrimientos existentes en su época respecto del 'origen de los juicios morales de valor'; no obstante señala a los trabajos de F. Nietzsche como los más profundos en estas materias, esto lo está diciendo Scheler treinta años después de la muerte del filósofo alemán. Es en este contexto

22 Ordo Amoris, p. 66. 
donde aparece la idea de 'resentimiento' como origen o fuente fundante de estos juicios. Al respecto, Scheler valora esta última afirmación, aun cuando no legitima el planteamiento nietzscheano en la que se asevera que 'el amor cristiano (moral cristiana) es la más fina flor de ese resentimiento ${ }^{23}$, ya que lo nuclear de la ética cristiana es el perdón, no el resentimiento, esta idea la madurará en el transcurso de su obra; esto, a propósito de los pasajes citados de la obra de Nietzsche. De hecho, el resentimiento es un concepto muy importante en Nietzsche, tesis que arremete contra el cristianismo, en tanto doctrina que promueve el resentimiento porque tiene 'una actitud resentida': es la actitud del hombre que es débil y termina por aceptar la sumisión, piedad o debilidad; que aspira a una especie de aceptación de los fuertes. Y esto hace que él vea el cristianismo como una forma de resentimiento.

Entonces entre Nietzsche y Scheler se produce un cambio de foco u orientación respecto de la definición de los valores a partir de la contraposición valórica que plantea Scheler desde la caracterización del 'resentimiento', toda vez que la idea de 'donación', 'generosidad', 'riqueza espiritual' que tiene el cristianismo (el amor cristiano), en el cuál el hombre 'se da' a los demás, esto no lo percibe Nietzsche.

En tal caso, desde esta perspectiva prefiere situar el 'resentimiento' desde la caracterización de la cosa (lo cual permite evidenciar el método fenomenológico) por sobre la definición verbal. En este sentido el resentimiento para Scheler es 'una autointoxicación psíquica' con causas y consecuencias bien definidas, que se funda en la descarga de ciertas emociones y afectos. Siendo asi se puede pensar que es como un envenenamiento de nosotros mismos, de nuestro interior donde las emociones y afectos que primero surgen son:

a. Sentimiento e impulso de venganza

b. Odio c. Maldad

d. Envidia

e. Ojeriza

f. Perfidia

Desde esta perspectiva el impulso de venganza es reactivo, acompañado de un acusado sentimiento de impotencia, punto de partida de la formación del 'resentimiento'. Entonces la venganza conseguida, para Scheler, hace desaparecer el sentimiento de venganza y, análogamente, el castigo de aquel a quien apunta el impulso de venganza, pero igualmente el verdadero perdón. Situación similar ocurre con la envidia y la perfidia. Pero la clarificación está en que ninguna de estas cuestiones constituye en si lo que es el resentimiento.

El resentimiento queda circunscrito a la relación asimétrica entre poder y subordinación, donde el sentimiento de venganza conduce a la 'sed de venganza', lo que a la vez siempre va a ser la 'actitud de la parte débil'. En este sentido, lo interesante es que en estas actitudes deben existir siempre 'relaciones simétricas', es decir, debe existir igualdad de nivel entre el ofendido y el ofensor. Por eso en estricto rigor, cuando un jefe ofende a su empleado, este último no experimenta ningún sentimiento de venganza debido a la asimetría de la interacción. El sentimiento de venganza se convierte en resentimiento cuanto más se transforma en un estado permanente 'ofensivo'.

Scheler realiza importantes alcances respecto del ámbito social en el sentido que cuanto más fatal aparezca una opresión social permanente, tantas menos fuerzas podrá desplegar para modificar prácticamente la situación y tanto más se desahogará en meras críticas de lo existente, sin fines positivos. Es aquí donde se funda lo que se denomina "crítica resentida", la cual se caracteriza por no querer 'en serio' lo que pretende querer; cuando realiza estas aseveraciones Scheler está pensando en el sistema político de Alemania.

23 Nietzsche. 'Genealogía de la moral'. Ensayo I, párrafos 8 y 14 . 
Para Scheler, la envidia ${ }^{24}$, los celos y la competencia forman un segundo punto de partida para el resentimiento. La 'envidia' surge del sentimiento de impotencia que se opone a la aspiración hacia algún bien, por el hecho de que otro lo posee. La envidia nace de la conciencia de la impotencia, y se caracteriza porque 'relaja la voluntad de adquirir', donde la envidia más impotente debe ser la 'envidia' más temible. En todos estos casos el origen del resentimiento va unido a una comparación valorativa de uno mismo con los demás.

La cuestión se complejiza cuando se añade a la tesis la impotencia, donde aparece la opresora coincidencia de inferioridad. Entonces, será a propósito de este punto que Scheler incorpora un aspecto central en el sistema filosófico de valores: la relación entre la conciencia del valor y los deseos y apetitos. Al amparo de lo anterior es que aparece pensado en Scheler el acto de la 'resignación', lo que prueba que la conciencia de los valores no se anula por fuerza cuando desaparece el poder de ambicionar, desde la óptica que solo el acto de la resignación nos libra de esta tendencia a ilusionarnos. Lo peculiar en la actitud interna de un hombre que calumnia los valores ajenos, no consiste en que los valores positivos ajenos no se le presenten como positivos, como altos valores.

Del mismo modo es interesante la reflexión que hace Scheler respecto de la forma y la medida en que el resentimiento se desarrolla en los grupos y en los individuos, los cuales van ligados, según el autor, a 'factores innatos del material humano' y a la estructura de la sociedad en que los hombres viven, en este sentido Scheler insiste en que el resentimiento siempre se desarrollará acompañado de un sentimiento de impotencia, a lo cual también denomina fenómeno de 'vida descendente'. Esto por una lado; pero, por otro, Scheler ilustra 'situaciones' que se van repitiendo típicamente, 'situaciones' que están cargadas de 'peligro de resentimiento'. Se cita el ejemplo de la mujer como sujeto, a quien le atribuye más debilidad ${ }^{25}$, y por lo tanto más vengativa y forzada por sus 'inmutables' cualidades personales, impulsos que quedan más reprimidos aún, porque las altas 'barreras del pudor' y las costumbres imponen a la mujer en este punto la mayor reserva. En esta misma ejemplificación Scheler sitúa a la 'mujer solterona', "...cuyos impulsos sexuales de reproducción y de ternura han sido reprimidos...", con lo cual estaría más expuesta a la 'flor del resentimiento', aun cuando ese resentimiento en este caso sea de carácter sexual:

"...esa caza de lo pecaminoso, que se convierte en obsesión en algunas solteronas, no es sino una última forma de satisfacción sexual, que se ha transmutado en satisfacción del resentimiento".... (Scheler, El resentimiento en la moral, p. 38, primer parágrafo).

Otra situación que cita Scheler como ejemplo de resentimiento es la generación adulta frente a la joven. Esto debido a que el 'atormentador' recuerdo de la juventud es rehuido y esquivado; y esto repercute entonces en la posibilidad de comprender a los jóvenes, existiendo simultáneamente al tendencia a negar aquellos valores específicos de las edades anteriores. En relación a lo anterior, eso sí, se admiten las variaciones históricas y contextuales, en tanto existen algunas culturas en que los 'viejos', por sus conocimientos y experiencias de vida, gozan de una estima y veneración que bastan para sofocar la génesis de resentimiento.

Un tercer ejemplo interesante respecto de las fuentes que fundan resentimiento citado por Scheler en su obra tiene relación con cuestiones que aparecen merced a las relaciones típicas entre los miembros de la

24 Scheler clarifica magistralmente de la siguiente forma a la envidia: "...puedo perdonártelo todo, menos que seas y que seas el que eres, menos que yo sea lo que tú no eres, que yo no sea tú", p. 28, "El resentimiento en la moral".

25 Esto es bastante complejo de analizar con cierta precisión en esta ocasión, debido a que llegan a mi memoria imágenes de las 'mujeres madres de la Plaza de Mayo' buscando a sus hijos, en Argentina; y en Chile la Agrupación de Detenidos Desaparecidos en la Dictadura Militar de Pinochet es dirigida por mujeres. Sería interesante analizar desde la perspectiva del resentimiento y del perdón este fenómeno en América Latina. 
familia y el matrimonio. En particular expone la figura de la 'suegra' y, en primer término, la madre del hijo, que es complejizada por la diversidad de sexo entre la madre y el hijo querido. Al respecto Scheler señala:

"... soportar - sin haber de reprimir odios y celos-que un ser amado desde su nacimiento, un ser para el cual se ha tenido todo género de cuidados y cuyo amor se ha poseido plenamente, se vuelva de súbito a otro ser $y$, por añadidura femenino, esto es, del propio sexo, se abrace a un ser que todavia no ha hecho nada por el objeto amado y que, sin embargo, se siente con el derecho de exigirlo todo; tener que soportar esto y además que alegrarse y congratularse cordialmente por ello y aun abrazar con amor a la recién llegada, he aquí una situación que no hubiera podido ser imaginada más arteramente por el diablo mismo para probar a un héroe".... (Scheler, El resentimiento en la moral. pp. 40-41).

En líneas generales me parecen interesantes las tesis de fondo que plantea Scheler sobre el resentimiento, en tanto experiencia de la impotencia ante la superioridad del otro, entonces esto se traduce en una vivencia de impotencia que genera un malestar ante el otro y un deseo de vencerlo. El ejemplo que tal vez cabe para la reflexión es lo que sucedió en Chile, así como en distintos paises de América Latina en la década de los setenta con la instalación de regímenes militares y el consiguiente quiebre de los procesos democráticos, particularmente sus consecuencias emocionales en quienes se vieron perjudicados con aquella coyuntura sociopolítica. Cuando se suicida Salvador Allende (presidente de Chile) el 11 de septiembre de 1973, en aquel momento, 'los vencedores' se enfrentaron a los vencidos. Ahora bien, muchas personas celebraron aquel hecho, to que denota resentimiento en varios sentidos, por eso mientras algunos lamentaban los hechos, otros celebraban festivamente. Luego hubo tortura, detenidos desaparecidos y muertos, así lo han revelado y confirmado actuales informes de investigación respecto de aquellos acontecimientos, que aún perviven en la memoria colectiva de la sociedad ${ }^{26}$. Por lo tanto, creo que ejemplos como este se pueden percibir con mayor nitidez la caracterización de resentimiento como 'intoxicación del alma', ya que sufre mucho quien está resentido; sufre porque se siente impotente, incapaz; no sabe cómo responder a determinadas acciones. Entonces también se podría describir como una pasión humana, probablemente contenida (en tanto no es expresada o exteriorizada), en este caso de las familias que permanecen buscando los cuerpos, sin embargo, no hay que confundir el deseo de justicia con el de resentimiento.

Scheler en este sentido nos entrega varias pistas, ya que nos dice que el resentimiento puede ser 'curado' a través de la ética del perdón, esto indistintamente que el resentimiento se pueda transmitir de generación en generación, y de hecho lo transmitimos, pero también puede ser curado. Esta es una cuestión fundamental, porque para algunos autores como Ricoeur to que entra en debate en cuestiones como las que se han señalado es la memoria, y desde esta perspectiva dice que 'un exceso de memoria puede hacer enfermar a un país', entonces comienza a aparecer el binomio perdón/olvido. Pero perdón no es olvido; ya que el olvido es la ausencia del recuerdo. Entonces, el perdón es 'el recuerdo salvado', redimido: "recuerdo lo que pasó, pero empecemos de nuevo'. Por lo tanto, desde este enfoque la ausencia de resentimiento, merced al perdón, evita la contaminación a las futuras generaciones que en-generen (creen) resentimientos respecto de conflictos que ellos ya no vivieron.

Scheler observa que la preeminencia de los valores utilitarios y materiales característica de esa moral por encima de lo agradable y de los valores que pertenecen al ámbito del crecimiento espiritual y de lo comunitario, genera precisamente una inversión en los valores: la exacerbación del deseo de poseer

26 Informe de la Comisión Nacional sobre prisión politica y tortura. (2005). Para muchos chilenos el informe constituyó una 'amarga sorpresa', según expresiones de familiares de las víctimas. 
en la sociedad; el tener por encima del ser, diríamos hoy en día, como percibiendo con esta expresión común el agudo problema en el que sin duda todos nos vemos afectados.

Pero como apunta Scheler, en la confusión de la crisis, la respuesta del resentimiento obedece al mismo sentido de la moral que lo engendra: las fuerzas irracionales que se despiertan siguen la violencia y la expresión del odio y la desesperación, para lograr, aunque sea en el instante del hecho destructivo, la revancha material, la igualdad ilusoria a partir de las cenizas de los bienes y los valores a los que se aspiraba. Sin embargo, amanece y todo se ve distinto y en lamentables ruinas, como en el despertar desconcertante y triste de aquel hombre ebrio que al llegar tarde en la madrugada a su casa, y luego de oír el obvio reclamo de su esposa, arremete contra todo el mobiliario, destrozándolo para afirmar que después de tanto trabajo él tiene derecho a divertirse y a que lo dejen dormir.

"Redefinir la escala valorativa", en palabras de Scheler, es lo que procede para volver a tomar un sentido más integral de lo humano; recuperar los valores del ser y la convivencia, de la construcción solidaria del bienestar, por encima de lo utilitario y material, pareciera describir una utopía, algo quizás inalcanzable. $Y$ aunque así suene, es nuestra única opción, pues cualquier camino que no intente esta redefinición, seguirá manteniendo el sistema de exclusión y la intoxicación moral latente. ¿Podemos impregnar este sentido a nuestro debate político, a nuestra maltrecha economía y a nuestro hacer cotidiano?

El resentimiento es un efecto reactivo ante la agresión, que en cuanto tal -es decir, si no interviene la razón humana encauzando o rectificando la reacción- tiene carácter negativo. Consiste en la respuesta ante la ofensa que se experimenta intimamente. Por eso, lo determinante en el resentimiento no radica en la ofensa en cuanto tal, sino en la respues- ta personal. $Y$ esta respuesta depende de cada quien, porque nuestra libertad nos confiere el poder de orientar de alguna manera nuestras reacciones. Covey advierte que "no es lo que los otros hacen ni nuestros propios errores lo que más nos daña; es nuestra respuesta. Si perseguimos a la víbora venenosa que nos ha mordido, lo único que conseguiremos será provocar que el veneno se extienda por todo nuestro cuerpo. Es mucho mejor tomar medidas inmediatas para extraer el veneno". Esta alternativa se presenta ante cada agresión: o nos concentramos en quien nos ofendió con su agravio y entonces surgirá el veneno del resentimiento, o lo eliminamos mediante una respuesta adecuada, no permitiendo que permanezca dentro de nosotros. Esto explica que el mismo fracaso de una empresa o idéntico desaire provocado por un poderoso, pueden sufrirlo varias personas a la vez y con la misma intensidad, pero que en unos cause solo un sentimiento fugaz de dolor, mientras que otros queden resentidos para toda la vida. ¿Es posible realmente orientar nuestras respuestas ante las ofensas para que no se conviertan en resentimientos?

\subsection{El restablecimiento scheleriano de la tesis socrática}

Para Scheler todo disvalor, nacido de la elección de aquello que posee un valor inferior en vez de aquello que posee uno superior, tiene que estar fundado en un engaño estimativo. Entonces, el mantenimiento de la tesis acerca de la relación entre el saber y el querer moral del hombre podría estar constituyéndose en un retorno a la tesis socrática según la cual la virtud no es más que la sabiduría, de modo que nadie hace el mal a sabiendas ${ }^{27}$. Esto se ratifica en la segunda sección del Formalismo ${ }^{28}$ :

"... Y en este sentido -más también solo en él-se restablece el principio de Sócrates de que todo 'querer bueno' está fundado en el 'conocimiento de lo bueno'; $y$, respectivamente, que todo querer malo descansa en un engaño y extravio mora-

27 Jenofonte. Recuerdos de Sócrates III, IX, 5 (trad. Agustín García Calvo).

28. Max Scheler, Der Formalismos in der Ethik un die materiale Wertethik, II, A, 5-GW 287-88. 
les". Esto es plenamente coherente con el sentido de la determinación individual a partir del contenido de esta, la cual aparece en virtud del acto de conocerse a si mismo, en expresión socrática.

Según Palacios J. M. (p. 54), Scheler estaria compartiendo plenamente con Sócrates la firme convicción de la verdad que la razón de la bondad o la maldad moral de un hombre cuyo saber moral le es evidente no está en la coincidencia de su querer con su saber, sino más bien en el carácter verdadero o erróneo de su conocimiento moral, o sea, la virtud es en el fondo sabiduria, y el vicio, engaño.

En este contexto, decir que una cosa designada con el adjetivo neutro o el sustantivo abstracto [lo justo, la justicia] es una excelencia (areté, virtud) implica que el predicado correspondiente puede utilizarse para alabar a alguien desde el punto de vista moral. Si la justicia es una virtud, entonces decir que alguien es justo es elogiarse moralmente por ese noble atributo. Por otro lado, 'ser feliz' es ante todo un atributo no moral, puesto que la felicidad (eudaimonia, prosperidad) se entiende como la posesión abundante de aquellas cosas que mejoran nuestra condición, y habitualmente la gente considera que esas cosas son los bienes morales. Entonces, lo que queremos decir es que en múltiples situaciones Sócrates declara la ignorancia sobre moral, más que la posesión de verdades en sí mismas. Esto también aparece al final del Libro I de La República, donde las conexiones entre felicidad y justicia, por ejemplo, no se clarifican porque no se halla ninguna definición satisfactoria de justicia. Este fracaso se torna evidente en el curso de una conversación apasionada y en ocasiones tensa. $Y$, sin embargo, la discusión en si era un intercambio de ideas libre y abierto, no existía urgencia por llegar a una decisión específica, práctica. Se somete a escrutinio una noción práctica, pero el escenario dramático deja en claro que la conexión con una opción real y con la acción es remota. Sócrates ha bajado a El Pireo para asistir al festival religioso y ha sido invitado a la casa de Céfalo. Tras escuchar las reflexiones de su anfitrión sobre la perspectiva de morir debiendo sacrificios a un dios o dinero a un hombre, es decir, sin haber reparado situaciones de injusticia, Sócrates aprovecha la situación para preguntar, en general, qué es la justicia. Sin embargo, no hay urgencia por resolver ningún caso concreto de injusticia. En rigor si se le toma en serio, la admisión final de ignorancia de Sócrates en el Libro I de La República no sabe si es bueno cumplir los requerimientos de la justicia, lo configura como alguien que ha abandonado drásticamente cualquier regla sensata para la acción moralmente correcta. "Justo" se considera en muchos contextos un predicado que caracteriza toda acción que sea moralmente correcta y loable. A su vez "bueno" supone un atributo que provee la razón última para hacer algo. De este modo, resulta dudoso que los amigos de Sócrates hayan sido inducidos a pensar que él había adoptado un agnosticismo moral radical, que lo dejaba desprovisto de toda justificación racional para comportarse de un modo honesto. Parece más verosímil pensar que esta parte de sus afirmaciones finales puede entenderse también como irónica. Esto reafirma la tesis que Sócrates si niega poseer conocimiento moral en algunos de los diálogos aporéticos tempranos. Sin embargo, estas negativas no deben entenderse como sinceras ni como insinceras y por lo tanto como negaciones que conducen a error. Mas si Sócrates no está siendo insincero, ¿por qué no abandona la actitud irónica y declara que sabe qué es la correspondiente excelencia moral? ${ }^{29}$.

\section{Bibliografía}

BENEDICTO XVI (2006) Deus Caritas. Primera Carta Encíclica de S.S. Benedicto XVI a los Obispos, a los Presbiteros y Diáconos, a las Personas Consagradas y a todos los fieles laicos sobre el amor cristiano. Editorial San Pablo. Santiago. Chile.

29 En este contexto del análisis resulta útil una breve revisión de algunos aspectos del Eufitrón en las conversaciones en el Pórtico del Arconte-Rey, en el ágora ateniense. A la luz de la declaración de Eufitrón, podremos entender la confesión de ignorancia de Sócrates como una negación de poseer creencias verdaderas o bien de que sus creencias estén definitivamente establecidas. 
BRENTANO, FRANZ (1952) Grundlegung und Aufbau der Ethik. Nach der Vorlersungen über "Praktische Philosophie" aus dem nachlass hrsg, von Franziska mayer-Hillebrand. A. Francke Verlag, Bern.

FERNÁNDEZ BEITES, PILAR. Ordo amoris normativo y persona como ser ideal. Universidad Pontificia de Salamanca.

FOWLES, JOHN (1968) The Aristos (ed. Rev.; London: Pan Books, 1968), p. 51.

GÓMEZ LOBO, ALFONSO (1998) La ética de Sócrates. Editorial Andrés Bello. Santiago. Chile.

NIETZSCHE, FRIEDRICH (1887) Genealogía de la moral. Traducción de Enrique López Castellón. Editorial Sígueme. Buenos Aires. Argentina.

PALACIOS, JUAN MIGUEL (2002) "Preferir y elegir en la ética de Scheler" en Revista de Occidente, pp. 39-55.

PINTOR-RAMOS, ANTONIO (1997) Scheler (1874- 1928). Ediciones del Orto [Biblioteca Filosófica]. Primera edición. Madrid. España.

RODRÍGUEZ DUPLÁ LEONARDO (2004) "San Francisco de Asís visto por Max Scheler", en Naturaleza y Gracia. LI.

SAN AGUSTÍN, De Doctrina Cristiana. L.I, XXVII, 28.
SANTO TOMÁS DE AQUINO (1970) Summa Theologica. Edición de la BAC. Madrid. España.

SCHELER, MAX (1996) Ordo amoris. Caparrós. Madrid. España.

SCHELER, MAX (1972): "Das tragische und die Werte". En Vom Umsturrz der Werte. Francke, Verlag, Berna y Munich,

SCHELER, MAX (1915) El resentimiento en la moral. Traducción de José Gaos y edición de José María Vegas. Caparrós Editores. Segunda edición (Colección Esprit, número 23), 1998.

SCHELER, MAX (1934) Ordo Amoris (traducción de X. Zubiri). Revista de Occidente. [Imprenta de Galo Sáez. Mesón de Paños 6].

SCHELER, MAX (1941). "Nuevo ensayo de fundamentación de un personalismo ético". II. Madrid, Revista de Occidente.

SCHELER, MAX (1954) Formalismus un die materiale Wertethik, Gesammelte Werke, Band 2, A. Francke Verlag, Bern-München.

SCHELER MAX (1957) Esencia y formas de la simpatía (traducido por José Gaos). Losada. Buenos Aires.

SCHELER, MAX (1960) El puesto del hombre en el cosmos (traducido por José Gaos). Losada. Buenos Aires.

SCHELER, MAX (1961) El santo, el genio y el héroe. Buenos Aires: Nova. 